\title{
Modification in body weight associated with antiepileptic drugs
}

\author{
Camilla N. De Gaspari ${ }^{1}$, Carlos A.M. Guerreiro²
}

\begin{abstract}
Antiepileptic drugs (AED) may cause body weight changes. Objective: To evaluate the dietary habits and body weight associated with AED in epileptic patients. Method: Sixtysix patients were subjected to two interviews, and had their weight and body mass index calculated and compared at both times, interval between six to eight months. Results: It was observed that $59.1 \%$ showed weight gain. The patients who had no weight gain had a greater proportion of individuals who engaged in some form of physical activity. However, of the 45 patients who maintained their initial dietary and medication pattern, $75.6 \%$ recorded a weight gain. Weight gain was seen in $66.7 \%$ of patients on carbamazepine $(n=18), 60 \%$ on valproate $(n=5), 50 \%$ on carbamazepine+clobazam treatment $(n=14)$, and $58.3 \%$ of patients on other(s) polytherapy $(n=12)$. Conclusion: The patient should be alerted to possible weight gain, and should be advised about dieting and participating in regular physical activity.
\end{abstract}

Key words: epilepsy, antiepileptic drugs, dietary habits, body weight.

\section{Alteração de peso corpóreo associado às drogas antiepilépticas}

\section{RESUMO}

Drogas antiepilépticas (DAE) podem causar alteração do peso corpóreo. Objetivo: Avaliar o hábito alimentar e do peso corpóreo associado às DAE em pacientes epilépticos. Método: Sessenta e seis pacientes foram submetidos a duas entrevistas, e tiveram peso e índice de massa corpórea (IMC) calculados e comparados nos dois momentos, com intervalo de 6 a 8 meses. Resultados: Apresentaram aumento de peso 59,1\% dos pacientes. Porém, os pacientes que não tiveram ganho de peso apresentaram maior proporção de indivíduos desenvolvendo alguma atividade física. Enquanto que dentre os 45 que mantiveram o padrão alimentar e medicação inicial $75,6 \%$ registraram ganho de peso. Observou-se ganho de peso em $66,7 \%$ dos pacientes com carbamazepina ( $n=18) ; 60 \%$ com valproato $(n=5) ; 50 \%$ com carbamazepina e clobazam $(n=14) ; 58,3 \%$ dos pacientes com politerapia $(n=12)$. Conclusão: Deve-se alertar o paciente sobre o ganho de peso, orientar quanto à dieta alimentar e, principalmente, incentivar atividade física regular.

\section{Correspondence \\ Carlos A.M. Guerreiro \\ Departmento de Neurologia \\ Faculdade de Ciências Médicas (FCM) \\ Universidade Estadual de Campinas (UNICAMP) \\ Rua Tessalia Viera de Camargo 126 \\ Caixa Postal 6111 \\ 13083-970 Campinas SP - Brasil \\ E-mail: guerreiro@fcm.unicamp.br \\ Funding support \\ Camilla N. De Gaspari received \\ a schollarship from Fundação de \\ Amparo à Pesquisa do Estado \\ de São Paulo (FAPESP)}

Received 30 August 2009

Received in final form 27 September 2009

Accepted 14 October 2009

Palavras-chave: epilepsia, drogas antiepiléticas, hábito alimentar, ganho de peso.

Conventional treatment for epilepsy involves antiepileptic drugs (AED) in mono- or polytherapy ${ }^{1}$. In the majority of patients the treatment is long-term. It is necessary to evaluate and monitor possible adverse effects during treatment, including body weight status ${ }^{2}$. Weight gain associated with AED is frequent, particularly with drugs such as valproate and carbamazepine as well as with gabapentine. The mechanism that causes weight gain varies according to the drug used, dose, sex, age, etc $^{2-4}$. These mechanisms are still not completely clear; among them are resistance to insulin leading to hyperinsulinemia in the case of valproate ${ }^{5}$, and in the case of carbamazepine, increased appetite favoring the deposition of fat by a mechanism still not well understood ${ }^{3}$.

Increase in weight is an undesirable effect that can interfere negatively with treatment, since it may reduce compliance

Department of Neurology, University of Campinas, SP, Brazil: ${ }^{1}$ Medical Student; ${ }^{2}$ Professor of Neurology. 
to treatment by lowering self-esteem as well as favoring and aggravating diseases such as hypertension and insulin resistance ${ }^{2-5}$

The aim of this study was to determine the status of appetite and body weight associated with the most frequent AED used by patients on mono- or polytherapy for epilepsy in an outpatient epilepsy clinic in a public hospital (Southeast Brazil), over a period of six to eight months.

\section{METHOD}

The study involved the evaluation of patients under treatment for epilepsy in the Epilepsy Outpatient Clinic of Hospital de Clinicas of the Campinas University (HCUNICAMP), from December 2007 to September 2008. The criteria considered for inclusion were: a signed informed consent form that had been submitted and approved by the Commission of Ethics in Research of the institution; patients at least 18 years old, cooperative, with reliable information, without evidence of mental retardation, with diagnosis of epilepsy well defined from a clinical viewpoint and confirmed by EEG and/or neuroimaging examinations; and patients who had been treated with the same AED for at least six months prior to the study period.

All patients were subjected to an initial interview with a questionnaire that obtained information about them (name, age, residence, education, socio-economic level), their epileptic seizures (age at first seizure, the seizure frequency, investigation tests, and seizure and syndrome classification), and about their medications and respective doses. As well, a food questionnaire was given to determine the dietary habits over a 24-hour period. The patients were also weighed and measured, and their body mass index (BMI) calculated ${ }^{6}$.

In the second interview, six to eight months after the first, another questionnaire was applied to review eating habits; changes in general appetite and taste for particular foods such as sweets and carbohydrates; whether the patient started some type of diet and/or physical activity; and finally, measurement of weight and calculation of BMI. Physical activity was defined as those who practiced regular physical activity, three times a week or more, for at least 30 minutes each time.

Patients were excluded from evaluations if they did not sign the informed consent form; did not cooperate with filling out the questionnaires or did not appear at scheduled visits; were referred for surgery for epilepsy; used other medications that are known to interfere with body weight status, such as antidepressants, corticosteroids and thyroid hormones; initiated dieting or physical activity in the interval between the interviews; and changed their therapeutic regimen of AED in the period between the first and second interview.

The organization of data was performed using stan- dardized forms, which were transcribed for electronic analysis. Next, checks for consistency were made, with the pertinent corrections.

Initially, a descriptive analysis of the study variables was performed. The results were presented in tables of frequencies for the qualitative variables. With respect to the quantitative variables, measures of central tendency and dispersion were estimated, and for those that did not show a normal distribution on evaluation by the Kolmogorov-Smirnov non-parametric test, the median accompanied by the minimum and maximum was used.

To compare proportions presented in associated tables, the chi-squared statistic was utilized, or the Fisher's exact test when necessary. Student's t-test was applied for the comparison of means.

The software used was Excel for making graphs and Stata (version 9.0) for statistical analysis.

\section{RESULTS}

In the period between December 2007 and September 2008, 150 patients were subjected to the first interview, which took place in the Epilepsy Outpatient Clinic of HC-UNICAMP.

The results presented here demonstrate that, of the two interviews conducted, 66 (44\%) patients appeared at both interviews conducted six to eight months apart, within the period mentioned above.

The purpose of this study was to evaluate the patients in relation to weight, body mass index (BMI), dietary habits and physical activity on arriving at the outpatient clinic and on their return to the unit, up till September 2008.

Half of the individuals studied (50\%) were males. At the initial clinic visit the patients had a mean age of 37.5 years (standard deviation of 13.7 years).

With regard to the frequency of seizures, $56.1 \%$ reported having had more than one seizure per month, and with respect to the drug therapy, $54.6 \%$ were in polytherapy treatment at the first visit. It should be pointed out that $81.8 \%$ of patients maintained the medication regimen they reported at the beginning of the study.

It was observed that $59.1 \%$ gained weight, with a mean increase of $3.9 \%$; $10.6 \%$ maintained the same weight and $30.3 \%$ showed of loss of weight with a mean decrease of 2.2\% (Table 1 and Figure). However, there was no statistically significant difference $(\mathrm{p}=0.92)$ in the distribution of body mass index between the two times they were measured (Table 2).

The patients who had weight gain did not differ from the others in relation to sex $(\mathrm{p}=0.80)$, mean age $(\mathrm{p}=0.62)$, initial $(\mathrm{p}=0.89)$ and final $(\mathrm{p}=0.35)$ therapies and dietary habits $(\mathrm{p}=0.39)$ (Table 3$)$. However, the patient group that had no weight gain included a greater proportion of individuals involved with some form of physical activi- 
Table 1. Mean gain and loss of weight in the patients studied, and mean gain and loss of weight in patients who took carbamazepine (CBZ) in mono- and polytherapy, and valproate (VPA) in mono- and polytherapy.

\begin{tabular}{lccc}
\hline & Median & Minimum & Maximum \\
\hline $\begin{array}{l}\text { Patients studied } \\
\text { Loss }(n=20)\end{array}$ & $1.45 \mathrm{~kg} / 2.2 \%$ & $0.10 \mathrm{~kg} / 0.1 \%$ & $13.70 \mathrm{~kg} / 14.8 \%$ \\
$\quad$ Gain $(\mathrm{n}=39)$ & $2.60 \mathrm{~kg} / 3.9 \%$ & $0.10 \mathrm{~kg} / 0.2 \%$ & $8.50 \mathrm{~kg} / 10.6 \%$ \\
CBZ & & & \\
$\quad$ Monotherapy $(\mathrm{n}=12)$ & $1.50 \mathrm{~kg} / 2.35 \%$ & $0.20 \mathrm{~kg} / 0.23 \%$ & $4.90 \mathrm{~kg} / 7.34 \%$ \\
$\quad$ Polytherapy $(\mathrm{n}=9)$ & $3.10 \mathrm{~kg} / 4.17 \%$ & $0.20 \mathrm{~kg} / 0.28 \%$ & $4.10 \mathrm{~kg} / 8.33 \%$ \\
VPA & & & \\
Monotherapy $(\mathrm{n}=3)$ & $5.70 \mathrm{~kg} / 7.08 \%$ & $1.20 \mathrm{~kg} / 1.61 \%$ & $7.60 \mathrm{~kg} / 10.63 \%$ \\
Polytherapy $(\mathrm{n}=7)$ & $2.60 \mathrm{~kg} / 4.34 \%$ & $2.00 \mathrm{~kg} / 2.83 \%$ & $8.50 \mathrm{~kg} / 9.37 \%$ \\
\hline
\end{tabular}

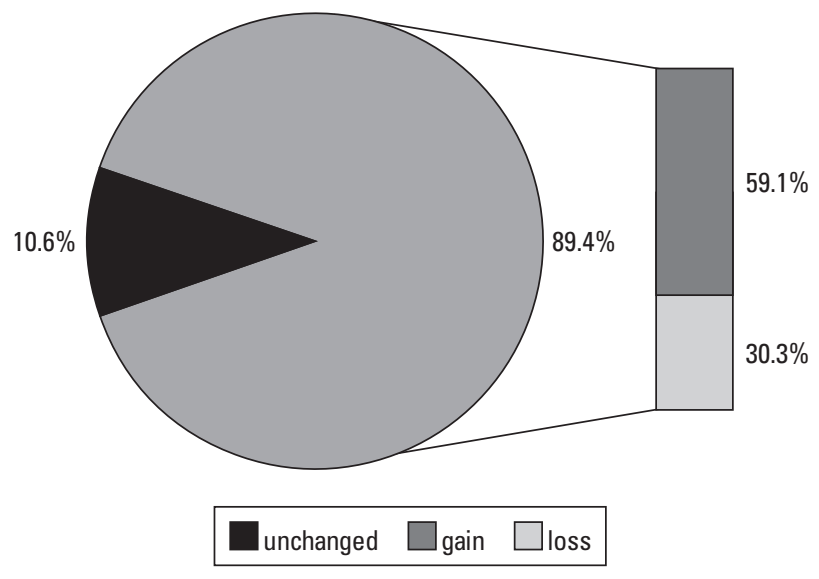

Figure. Profile of weight of patients with epilepsy, who maintained the same medication and were present at the two interviews in the period stipulated.
Table 2. Distribution of the body mass index (BMI, in $\left.\mathrm{kg} / \mathrm{m}^{2}\right)$ in the first and second interview.

\begin{tabular}{|c|c|c|}
\hline BMI $\left(\mathrm{kg} / \mathrm{m}^{2}\right)$ & $\begin{array}{c}1^{\text {st }} \text { interview } \\
\text { No. }(\%)\end{array}$ & $\begin{array}{c}2^{\text {nd }} \text { interview } \\
\text { No. (\%) }\end{array}$ \\
\hline $\begin{array}{c}<20 \\
\text { (underweight) }\end{array}$ & $5(7.6)$ & $4(6.1)$ \\
\hline $\begin{array}{c}20 \text { to } 24.9 \\
\text { (normal weight) }\end{array}$ & $25(37.9)$ & 25 (37.9) \\
\hline $\begin{array}{c}25 \text { to } 29.9 \\
\text { (overweight) }\end{array}$ & $20(30.3)$ & $17(25.8)$ \\
\hline $\begin{array}{c}30 \text { to } 34.9 \\
\text { (obese grade I) }\end{array}$ & $11(16.7)$ & $15(22.7)$ \\
\hline $\begin{array}{c}35 \text { to } 39.9 \\
\text { (obese grade II) }\end{array}$ & $3(4.6)$ & $4(6.1)$ \\
\hline $\begin{array}{l}40 \text { or higher } \\
\text { (obese grade III) }\end{array}$ & $2(3.0)$ & $1(1.5)$ \\
\hline
\end{tabular}

Table 3. Distribution of the 66 patients according to sex, age, medication, dietary habits, exercising and alteration in weight.

\begin{tabular}{|c|c|c|c|c|}
\hline \multirow[b]{2}{*}{ Variable } & & \multicolumn{2}{|c|}{ Weight gain } & \multirow[b]{2}{*}{$p$ value } \\
\hline & & Yes - No. (\%) & No - No. (\%) & \\
\hline \multirow[t]{3}{*}{ Sex } & & & & 0.80 \\
\hline & Female & $20(51.3)$ & $13(48.1)$ & \\
\hline & Male & $19(48.7)$ & $14(51.9)$ & \\
\hline \multirow[t]{3}{*}{ Age } & & & & $0.62^{*}$ \\
\hline & Mean & 36.8 years & 38.5 years & \\
\hline & Standard deviation & 14.2 years & 13.1 years & \\
\hline \multirow[t]{3}{*}{ Less than 1 seizure/month } & & & & 0.66 \\
\hline & No & $18(46.1)$ & $11(40.7)$ & \\
\hline & Yes & $21(53.9)$ & $16(59.3)$ & \\
\hline \multirow[t]{3}{*}{ Therapy at $1^{\text {st }}$ interview } & & & & 0.89 \\
\hline & Mono & $18(46.1)$ & $12(44.4)$ & \\
\hline & Poly & $21(53.9)$ & $15(55.6)$ & \\
\hline \multirow[t]{3}{*}{ Therapy at $2^{\text {nd }}$ interview } & & & & 0.35 \\
\hline & Mono & $19(48.7)$ & $10(37.0)$ & \\
\hline & Poly & $20(51.3)$ & $17(63.0)$ & \\
\hline \multirow[t]{3}{*}{ Dieted } & & & & $0.39^{* *}$ \\
\hline & No & $24(88.9)$ & $37(94.9)$ & \\
\hline & Yes & $3(11.1)$ & $2(5.1)$ & \\
\hline \multirow[t]{3}{*}{ Praticed RPA } & & & & $0.04^{* *}$ \\
\hline & No & $38(97.4)$ & $22(81.5)$ & \\
\hline & Yes & $1(2.6)$ & $5(18.5)$ & \\
\hline
\end{tabular}

*Student's t-test; **Fisher's exact test; RPA: regular physical activity. 
ty $(\mathrm{p}=0.04)$. It was also noted that among the 66 patients with epilepsy studied, 61 (92.4\%) reported having maintained the same dietary habits between the first and second interview.

Among the patients who had an increase in weight ( $n=39$ ), only $23.1 \%$ noted a greater appetite and $20.5 \%$ noticed a greater consumption of sweets and carbohydrates.

On the other hand, of the nine patients who used medications that could alter weight, such as antidepressants, corticosteroids and thyroid hormones, none showed weight gain.

Of the 45 patients who maintained their initial medication and eating pattern, and who did not follow any diet program or even exercised regularly, $75.6 \%$ showed a weight gain.

In addition, weight gain was seen in the following: $66.7 \%$ of patients on monotherapy carbamazepine $(\mathrm{n}=18)$, with a dose between 200 and $2200 \mathrm{mg}$ per day $($ mean $=844.4$ mg; mean gain $=2.35 \%)$ (Table 1$) ; 60 \%$ of patients on monotherapy valproate $(n=5)$ with a dose between 750 and $1250 \mathrm{mg}$ per day (mean=950 mg; mean gain $=7.08 \%$ ) (Table 3 ); $50 \%$ of patients on polytherapy carbamazepine+clobazam $(\mathrm{n}=14)$, with a dose of carbamazepine between 600 and $1400 \mathrm{mg}$ (mean=972 $\mathrm{mg}$ ) per day and of clobazam of 5 to $40 \mathrm{mg}$ (mean=24.4 mg); 58.3\% of patients on polytherapy valproate+other(s) $(n=12)$, with a dose of valproate varying between 250 and 1500 mg per day $($ mean $=916.7 \mathrm{mg})$. One patient on monotherapy with lamotrigine showed a weight gain $(0.17 \%$ of previous weight, that is, $100 \mathrm{~g}$ ) with a dose of $200 \mathrm{mg}$ per day.

\section{DISCUSSION}

The status of body weight is determined by many factors, among which are psychological aspects, diet, regular physical exercise and use of medications. This study was not designed to draw definitive conclusions about weight gain or loss.

In this study, the data from 66 patients who were able to be interviewed twice was analyzed. Fifty-nine percent of patients gained weight. There were no significant differences in sex, mean age, frequency of seizures, and whether or not the patient was dieting. We do not know the true compliance of the patients to their diets, as only a small sample kept a food intake log. Of these, 92.4\% apparently maintained the same eating pattern.

However, the majority of patients who did not gain weight, irrespective of the AED taken, were engaged in regular physical activity.

It has been demonstrated that physical exercise, besides improving physical condition and controlling weight, also improves cognitive function in adults at risk of developing Alzheimer's disease ${ }^{7,8}$. Whether this finding holds true for persons with epilepsy is not known.
It is known that a modification in body weight is a common finding in treatment with $\mathrm{AED}^{4,9}$ and this impairs treatment since it aggravates other existing diseases such hypertension, heart disease, dyslipidemia and diabetes, as well as affecting the self-esteem of the patient ${ }^{10-12}$. The weight gain occurs through alterations in the metabolism of glucose and lipids, but the exact mechanism is not yet well understood ${ }^{13}$.

Weight gain was observed in $75.6 \%(n=45)$ of patients who maintained the same medication and eating pattern, and who neither used medications that altered weight nor initiated dieting or physical activity. Despite the limitations of the findings, it is interesting to note that only one-quarter of the patients experienced an increase in appetite and one-fifth referred to an increased consumption of sweets.

With regard to type of medication, as in other studies, weight gain appeared to be more related to carbamazepine and valproate ${ }^{3,5,14}$. Here, weight gain was found in $66.7 \%$ of patients on monotherapy with carbamazepine, as well as in $60 \%$ of patients on monotherapy with valproate. However, the patients on monotherapy with carbamazepine had a mean increase in weight of $2.35 \%$ while the patients on monotherapy with valproate had a mean increase of $7.08 \%$. The median was also four times greater in patients on monotherapy with valproate than those who were on monotherapy with carbamazepine. Polytherapy with carbamazepine and clobazam, the most frequently-used combination, showed a weight gain in 50\% of patients and probably explains the greater median in the patients on polytherapy with carbamazepine than in patients on polytherapy with valproate.

The population of patients who attend an epilepsy outpatient clinic of a tertiary hospital is generally made up of those with focal epilepsies that are difficult to control or even refractory to AED. In the sample studied, more than half had more than one seizure per month and took more than one AED (polytherapy). One possible explanation for the finding of more frequent weight gain in patients on carbamazepine than on valproate was probably due to the higher mean dose of carbamazepine compared to valproate, besides the aforementioned combination with clobazam. This last therapy has a gabaergic mechanism of action, which potentiates weight gain. Easter et al. ${ }^{15}$ reported that weight gain occurred in children on valproate. Among 211 patients (103 on valproate and 108 on carbamazepine), there was an objective difference in weight gain between the two groups of patients. Some of these patients switched medication due to a lack of efficacy and continued to gain weight on carbamazepine. The authors concluded that weight gain could be erroneously attributed to treatment only with valproate ${ }^{15}$.

Lamotrigine is considered an AED that does not interfere with body weight $t^{4,16}$. In the present study, an in- 
crease in weight was seen in the patient on monotherapy with lamotrigine, but it only amounted to a gain of $100 \mathrm{~g}$, which was not statistically significant.

One limitation of the study was the loss to follow-up between interviews, which decreased the number of patients in the final analysis. Only forty-five of 66 patients (68\%) kept their medication, eating habits during the whole period of evaluation. Another bias in the study was in relation to the analysis of dietary habits, based on the the patient's record keeping of their diet, which only indicated an estimate of dietary habits. Thus, further studies are warranted with a larger number of patients, in which it would be possible to observe weight change in patients on mono- and polytherapy for epilepsy.

Weight gain is a frequent adverse effect in patients on treatment with AED, in mono- as well as polytherapy, independent of sex and age. Therefore, on initiating therapy with AED, clinicians should opt for drugs that do not interfere with body weight and, if possible, they should alert patients of potential undesirable effects and encourage the patients to be on a diet and, especially, to engage in regular physical exercise.

\section{REFERENCES}

1. Guerreiro CAM, Guerreiro MM. Tratamento das epilepsias recém-diagnosticadas. In: Guerreiro CAM, Guerreiro MM (Eds). Epilepsia: o paciente otimamente controlado, São Paulo: Lemos, 1999;1:59-72.
2. Pijl $H$, Meinders AE. Bodyweight changes as an adverse effect of drug treatment. Mechanisms and management. Drug Saf 1996;14:329-342.

3. Jallon P, Picard F. Bodyweight gain and anticonvulsants: a comparative review. Drug Saf 2001;24:969-978

4. Biton V. Effect of antiepileptic drugs on bodyweight: overview and clinical implications for the treatment of epilepsy. CNS Drugs 2003;17:781-791.

5. Pylvänen V, Knip M, Pakarinen $A$, et al. Serum insulin and leptin levels in valproate-associated obesity. Epilepsia 2002;43:514-517.

6. Prado FC, Ramos JA, Valle JR. Obesidade: atualização terapêutica 2007: manual prático de diagnostic e tratamento. 23a Ed. São Paulo: Ed Artes médicas 2007:332-334.

7. Lautenschaler Nt, Cox KL, Ameida OP, et al. Effect of physical activity on cognition in older adults at risk for Alzheimer disease. JAMA 2008;300: 1028-1037.

8. Larson EB. Editorial: physical activity for older adults at risk for Alzheimer disease. JAMA 2008;300:1077-1079.

9. Ness-Abramof R, Apovian CM. Drug-induced weight gain. Timely Top Med Cardiovasc Dis 2005;28,9:31.

10. Perucca E, Meador KJ. Adverse effects of antiepileptic drugs. Acta Neurol Scand 2005;181(Suppl):S30-S35.

11. Biton V. Weight change and antiepileptic drugs: health issues and criteria for appropriate selection of an antiepileptic agent. Neurology 2006;12:163-167.

12. Ruetsch O, Viala A, Bardou H, et al. Psychotropic drugs induced weight gain: a review of the literature concerning epidemiological data, mechanisms and management. Encephale 2005;31:507-516.

13. Sheth RD, Montouris G. Metabolic effects of AEDs: impact on body weight, lipids and glucose metabolism. Int Rev Neurobiol 2008;83:329-346.

14. Zimmermann $\mathrm{U}$, Kraus $\mathrm{T}$, Himmerich $\mathrm{H}$, et al. Epidemiology, implications and mechanisms underlying drug-induced weight gain in psychiatric patients. J Psychiatr Res 2003;37:193-220.

15. Easter D, O'Bryan-Tear CG, Verity C. Weight gain with valproate or carbamazepine: a reappraisal. Seizure 1997;6:121-125.

16. Devinsky O, Vuong A, Hammer A, Barrett PS. Stable weight during lamotrigine therapy: a review of 32 studies. Neurology 2000;54: 973-975. 